Марченко Елена

кандидат психологических наук, доцент кафедры психологии

Брестского государственного университета имени А.С. Пушкина http://orcid.org/0000-0002-1671-584X.

DOI https://doi.org/10.35619/prap_rv.vi14.164

\title{
АНАЛИЗ ЗАБЛУЖДЕНИЙ ОТНОСИТЕЛЬНО МЕТАФОРИЧЕСКИХ АССОЦИАТИВНЫХ КАРТ КАК ИНСТРУМЕНТА ПСИХОЛОГИЧЕСКОЙ ПОМОЩИ
}

\begin{abstract}
Аннотация. В статье представлен анализ наиболее распостраненных ошибочных представлений о метафорических ассочиативных картах. Объяснены причины их возникновения у клиентов и психологов, а также описаны способы их преодоления. Доказывается, что это достаточно апробированный психологический инструментарий, действенность которого имеет строго научное обоснование. Обосновывается почему метафорические асоииативные карты сами по себе не могут рассматриваться в качестве диагностического инструмента. Систематизованы преимущества метафорических ассоциативных карт в сфере психологического консультирования и психотерапииї (широкий спектр завданий, форм роботы, возможность использовать специалистами различных психологических направлений; экологичность для клиента, привлечение ресурсов сознания и подсознания для решения проблемы; ускорение решения различных задач; создание общего символического кода для клиента и спечиалиста; гибкие правила работы; привлекательность для клиентов разных возрастных групп). Рассмотрень основные ограничения и противопоказания $\kappa$ применению данного инструмента в психологической практике. Рассмотрены, какие механизмы психологической защиты могут быть преодолены с помощью метафорических ассочиитивных карт (вытеснение, диссочиачия). Описаны ключевые механизмы, которые обеспечивают актуализацию проблем клиента (ассоциации, проекция, идентификация) и собственно терапевтические механизмы карт (диссочиация, осознание, децеентрация, метафоризаџия, осмысления).
\end{abstract}

Ключевые слова: метафорические ассочиативные карты, консультирование, достоинства, ограничения, заблуждения, защитные психологические механизмы

Постановка проблемы. Метафорические ассоциативные карты - один из психологических инструментов, который завоевывает все большую популярность, привлекая внимание не только практиков различных специализаций (психологов, психотерапевтов, специалистов по социальной работе, педагогов, коучей, HR-менеджеров, душепопечителей и др.), но и ученых. Об этом свидетельствует регулярное появление новых колод, тематических «бумажных» и интернетизданий, посвященных вопросам использования МАК в работе с различными клиентами и по решению различных проблем, а также увеличение числа бесплатного контента и платных курсов по освоению данного инструмента.

Столь быстрое распространение и популяризация с одной стороны создает условия для обобщения опыта использования МАК с целью оказания психологической помощи, а с другой - в силу привлекательности для неспециалистов - дает почву для распространения различных заблуждений, которые могут иметь различные негативные последствия как для отдельных клиентов, так и самих специалистов.

Цель статьи заключается в том, чтобы рассмотреть типичные заблуждения относительно МАК и способы их преодоления.

\section{Основное содержание.}

Тезис №1 «МАК - новый психологический инструмент».

С одной стороны данный тезис используют многие психологи, создавая ореол инновационности и таким образом привлекая клиентов. Однако данный тезис применим 
исключительно к постсоветским территориям, так как первый обучающий семинар по МАК был проведен израильским психологом Любовью Мошинской в начале 2000-х годов. В Украине М. Эгетмейер и О. Аялон провели первый семинар в 2008 году (Милорадова и Попова, 2016). В тоже время история использования МАК в мировой практике составляет уже почти 40 лет. Первая колода, так называемые «О-карты» («Oh-cards» - от междометия в английском языке выражающего удивление) впервые была опубликована в 1981 году в Канаде, а в 1985 году - в Германии (Киршке, 2010). За эти годы карты получили широкое распространение и были переведены на 17 языков мира. За столь долгий опыт использования накоплен достаточный опыт, свидетельствующий в пользу эффективности техник с использованием МАК в различных направлениях консультирования, психотерапии, коррекционно-развивающей работы и других видах помощи.

\section{Тезис №2 «МАК = магия».}

В. Киршке (2010) отмечает, что «Каждый, кто занимается ассоциативными картами, рано или поздно придет к удивительному выводу: многие карты, вытянутые вслепую, поразительным образом попадают в точку и отражают жизненную ситуацию игрока настолько точно, что думаешь: «Это не может быть случайностью!» (с. 128). Отчасти ситуация осложняется тем, что МАК ассоциируются с картами ТАРО или в принципе с гаданием на игральных картах. Более того существует и вариаций МАК, использующих образы-идеи ТАРО («Карты снов и фантазий» С. Каплан-Уильямс, «Архетипические карты» К. Майсс, «Карты сновидений» Дж. Паркер).

Так называемая магическая реальность (Е. В. Субботский) уже с раннего детства представлена в сознании ребенка. Она воплощена в сказках, художественной литературе, фантастических кинофильмах и художественных полотнах. Более того, указывается, что психика человека испытывает потребность в погружении в мир магического и волшебного (Казанцева, 2017). Это объясняется тем, что в рамках фантастического мира человек получает надежду на решение имеющейся у него проблемы чудесным образом, т.е. без собственных усилий. Особенно явно это обнаруживается в отношении клиентов при внешнем локусе контроля, с выраженной мотивацией решения проблемы при истощенных ресурсах (Казанцева, 2017; Кац и Мухаматулина, 2016; Попова и Милорадова, 2014; Ушакова, 2017).

Решение видится в том, чтобы объяснить клиенту принцип работы с МАК, убрать из диалога всю терминологию, которая может ассоциироваться с гаданием («расклад», «колода»), использовать техники «в открытую».

Тезис №̄3 «МАК - уникальный «автономный» инструмент диагностики и оказания психотерапевтического воздействия».

С точки зрения классификации методов по содержанию получаемой информации, МАК относится с инструментами, позволяющими лишь собирать информацию проективного характера. Методики данной группы, с одной стороны, имеют сходства с методом анализа продуктов деятельности человека (в данном случае - выбора определенных карточек), а с другой - в обязательном порядке предполагают проведение клинической беседы. Таким образом, не карточки сами по себе, а исключительно анализ всех вербальных (интерпретация клиентом изображений) и невербальных проявлений позволяют специалисту сделать то или иное заключение о состоянии клиента. Важно понимать, что МАК не является собственно диагностической методикой, так как не проходят процедуру валидизации. Сами по себе они не позволяют квалифицировать психические состояния, но могут быть использованы как стимульный материал для сбора информации (Кац и Мухаматулина, 2016; Попова и Милорадова, 2014; Ушакова, 2017).

Как указывают Попова и Милорадова (2014), к картам применим принцип отношения фигуры и фона: объекты, соотносимые со значимыми мотивами, переживаниями, занимают центральное место в сознании (фигура), а менее значимая или нейтрально окрашенная информация отступает на задний план и образует фон. На этом основании базируется главный «закон» работы с МАК «хозяин карты - хозяин истории», указывающий что ни одна карта не имеет определенного («правильного») значения. 
В рамках коррекционно-развивающей работы, консультирования или психотерапии МАК также не являются самостоятельной «методикой». Так, не отдельные наборы карточек или определенные техники оказывают психологическое воздействие и обеспечивают решение проблемы. МАК выступают лишь стимульным материалом, эффективность и использования которых с одной стороны определяется спецификой общего подхода оказания психологической помощи (психоаналитического, когнитивно-поведенческого, гештальтерапии и т.д.), а с другой грамотностью конкретного специалиста.

\section{Тезис №4 «МАК - действенный инструмент для всех и на все случаи жсизни».}

Реклама различных наборов МАК, обучающих вебинаров и программ пестрит смелыми обещаниями. Нередко в отношении МАК можно услышать такие характеристики, как «подходят всем» «решают любые вопросы», что не соответствует реальности. Проведенный анализ литературы позволяет выделить следующие достоинства и преимущества МАК.

1. Широкий диапазон использования. Ассоциативные карты как инструмент, используются психологами различных психотерапевтических школ в работе с клиентами широкого возрастного диапазона, уровня образования, любых национальностей и вероисповедания. Более того, карты значительно облегчают работу с клиентами, испытывающими сложности вербализации своих переживаний из-за низкого уровня образованности или низкого уровня вербального интеллекта. МАК - также универсальный инструмент с точки зрения формата, этапов (задач) консультирования. Так, МАК потенциально могут быть использованы, как в индивидуальной, так в парной или групповой работе. В группах знакомых (семьи, школьные классы, спортивные команды, трудовые коллективы) или незнакомых участников (тренинги с открытым набором участников). Также карты соотносятся с решением, как вспомогательных, так и основных задач консультирования (см.табл. 1.).

Таблийа 1.

Задачи консультирования, решаемые с помощью МАК

\begin{tabular}{|c|c|c|}
\hline Вспомагательные & Промежуточные & Терапевти \\
\hline $\begin{array}{ll}\text { - } & \text { установление контакта; } \\
\text { - } & \text { уточнение запроса; } \\
\text { - } & \text { оценка актуального } \\
& \text { эмоционального состояния } \\
& \text { клиента; } \\
\text { - } & \text { оценка эффективности } \\
& \text { работы и т.п. }\end{array}$ & 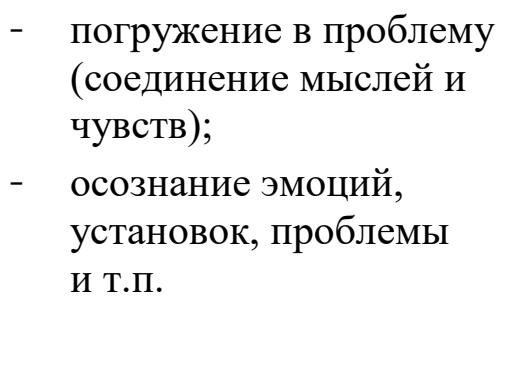 & $\begin{array}{ll}\text { - } & \text { эмоциональное } \\
\text { отреагирование; } \\
\text { - } & \text { расширение } \\
\text { осознания ситуации; } \\
\text { - } & \text { рефреминг; } \\
\text { - } & \text { поиск ресурсов; } \\
\text { - } & \text { интеграция Я и т.п. }\end{array}$ \\
\hline
\end{tabular}

2. Экологичность. Ассоциативные карты дают возможность клиенту максимально безопасно спроецировать на них свое внутреннее состояние. Клиент получает возможность говорить как бы не о себе, а о карте. И таким образом регулировать степень самораскрытия и «погружения» в проблему. Более того, в процессе работы карту можно перевернуть, убрать, отодвинуть, переместить на выбранное клиентом расстояние, что также рассматривается как довод в пользу экологичности данного инструмента.

3. Привлечение ресурсов бессознательного для решения проблемь.

В структуре сознания, согласно взглядам А. Н. Леонтьева, изначально формируется чувственная ткань. При этом психологи солидарны, что основными для человека выступают зрительные образы. В то время как вербальный «слой» (система значений) добавляется на много позже. Именно этим и объясняется эффективность МАК в проработке различного рода проблем, осознание которых затруднено защитными механизмами. За счет привлечения ресурсов бессознательного специалист получает возможность прорабатывать состояния, связанные с ситуациями, которые не представлены четко в памяти клиента. Например, это могут быть ситуации из раннего детства или же вытесненные истории и состояния, блокируемые 
рациональными барьерами (Морозовская, 2015). С помощью МАК можно прийти к порождению личностных смыслов за пределами рационального опыта (Казанцева, 2017).

Это достоинство имеет и еще одно проявление. Работа с МАК как для клиента, так и для самого специалиста может актуализировать новое неожиданное направление диалога, размышлений. Приходя к психологу клиенты, как правило, имеют определенные представленияожидания о том, как должна проходить встреча, о чем и как рассказывать. И для описании обсуждаемых ситуаций, как правило, они также используют определенные шаблонные схемы. В свою очередь специалист также выстраивает определенную логику встречи, задает вопросы, выводит клиента на обсуждение определенных тем. Появление той или иной карточки (изображения/надписи) может «разорвать» этот шаблон, дать неожиданную реакцию, мысль, к которой бы ни клиент, ни специалист не подошли бы в процессе работы. Особенно очевидно это обнаруживается при использовании стратегии «в закрытую», когда клиент вытягивает карточки наугад.

4. МАК - ускоритель работы. Данный тезис относится к различным задачам (установления контакт, формулирование запроса, поиск ресурсов и т.п.). Это обусловлено стимулирующей и фокусирующей функциями МАК (Кац и Мухаматулина, 2016). Картинки активизируют осмысление и выступают как триггеры для воспоминаний различных модальностей. В отличие от проективных рисуночных методик, использование которых осложняется не только временными затратами, но и переживаниями клиентов по поводу их художественных способностей, МАК позволяют работать с уже готовыми изображениями. Можно сказать, что изображения, представленные в колодах метафорических ассоциативных карт, представляют собой опредмеченные вариации различных состояний, переживаний мыслей, моделей поведения и т.п.

МАК - это стимульный материал, дающий мультимодальную сенсорную стимуляцию, создающую путем неосознанных ассоциаций метафорические образы, способствующие диссоциации субъекта с актуальной проблемой, в результате чего возникает возможность ее ассоциативного и нарративного исследования, а также переноса внутренних побуждений и неосознанных потребностей в зону рационального осмысления (Ингерлейб, 2020, с. 14).

5. Создание общего для клиента и специалиста контекста, системы обозначений при обсуждении той или иной ситуации. Это преимущество связывают с так называемой коммуникативной, или экспрессивной функцией карт (Ингерлейб, 2020), а также в целом с поясняющей функцией метафор в терминологии Д. Трунова (1997). МАК выступают как средство передачи информации от клиента специалисту. С помощью карт психолог может составить своеобразный словарь образов, которые использует клиент для описания себя и своего мировосприятия. И в дальнейшем при формулировании своих сообщений использовать эти обозначения. Таким образом у клиента создается впечатление «меня понимают», что значительно облегчает установление контакта и переход собственно к решению проблемы.

6. Гибкие правила использования - в отличие от ряда психологических инструментов МАК выступают стимульным материалом, который можно использовать самыми разнообразными способами: разрабатывать новые техники, адаптировать существующие приемы под требования актуальной ситуации. Они дают широкое поле для экспериментирования и проявлений творчества специалиста (Олифирович и Малейчук, 2018).

7. Привлекательность для клиентов объясняется несколькими моментами. Во-первых, МАК - это яркая наглядность. Во-вторых, работа с проективными картами проходит в форме игры. Особенно актуально это для детей и подростков, которым сложно выдержать сессию только на вербальном уровне (Ушакова, 2016).

Особая сложность связана с тем, что помимо собственно психологических наборов МАК появляются и карты, которые используются в коучинге или душепопечении.

Несмотря на все рассмотренные достоинства, ведущие специалисты указывают на определенные ограничения и даже противопоказания для использования МАК (Ингерлейб, 2020; Кац и Мухаматулина, 2016; Олифирович и Малейчук, 2018; Ушакова, 2017 и др.). Рассмотрим их.

Возрастные ограничения объясняются особенностями развития сознания и мышления. Считается, что отдельные наборы могут быть использованы с детьми, начиная со старшего 
дошкольного возраста, когда ребенок становится способными выделять суть изображенной на картинке ситуации и соотносить ее с событиями из собственного опыта (Ушакова, 2016). В целом же ограничения связаны не столько с МАК как инструментом в принципе, но прежде всего с особенностями используемых изображений (степенью их метафоричности) и задачами. На сегодняшних день можно обнаружить ряд специальных детских наборов, которые позволяют работать с детьми («Усатый - Полосатый» Л. Гаценко, «Волшебный сундучок» И. Васильевой и М. Лебедевой, «Волшебные помощники из добрых сказок» О. Степановой, «Роботы» Т. Ушаковой и др.). Данные наборы могут быть использованы как сами по себе, так и в сочетании с другими подходов оказания психологической помощи детям (например, сказкотерапии).

В числе индивидуальных особенностей клиентов, которые затрудняют работу с МАК, можно указать следующие. Во-первых, это мировоззренческие установки, когда карты рассматриваются клиентом как эзотерическая практика, магия и т.п. В таком случае специалисту следует убрать из речи всю терминологию, которая может ассоциироваться с гаданием («расклад», «колода»), а также объяснить суть работы с МАК. Во-вторых, это так называемая конкретность мышления и сложности понимания переносных значений, метафор как таковых. В таком случае лучше отказаться от наборов с выраженной символичностью, многозначностью и использовать карточки для опознания и обсуждения отдельных ситуаций («Исцеление внутреннего ребенка» вместо «Детство глазами художниками», «Ресурсы» вместо «Точка опора», «Женщина глазами художника» / «Мужчина глазами художника» Федоровой вместо «Дерево как образ человека» Кац, Мухаматулиной, «Любовь глазами художника» Федоровой вместо «Дуэт». Шмулевича и т.д.).

Особые случаи составляет работа с клиентами, имеющими психиатрическую патологию или пограничные состояния. В зависимости от нарушения специалисты либо рекомендуют вообе отказаться от использования МАК, либо использовать наборы с максимально конкретными изображениями и лишь на определенных этапах работы (Динкель и Сорокина, 2013; Казанцева, 2017; Ушакова, 2017 и др.). В контексте с данным ограничением ведущие специалисты не рекомендуют использовать МАК на первой консультации, когда психологических и психиатрический статус клиента неясен.

Как отмечает Т. О. Ушакова (2017), помимо собственно противопоказаний есть и просто индивидуальные предпочтения, когда МАК как инструмент работы не нравятся самому психологу или клиентам.

\section{Тезис №5 «МАК - это карточки и определенные техники»}

Проведенный анализ изданий и интернет-контента, посвященных МАК, свидетельствует о том, что основной упор авторы делают на презентации конкретных техник, которые потенциально может использовать любой обыватель даже без специалиста. Отчасти это связано с тем, что изначально карты были созданы канадским художником Эли Раманом как игра, а не психологический инструмент. В. Киршке в одной из первых книг-руководств по использованию МАК «Клубника за окном» (2010) использует обозначение «игра».

На то, что карточками может пользоваться любой человек с целью «самопознания» или развлечения указывают многие практики, подобного рода информацию можно встретить и в инструкциях, прилагающихся к наборам метафорических ассоциативных карт.

В целом же наиболее характерен данный тезис для платных обучающих программ, разработанных психологами-практиками и обильно представленных в интернете. В то время как ведущие специалисты по МАК (Эгетмейр, Мошинская, Морозовская, Горобченко, Тальпис, Кац, Мухаматулина, Ушакова и др.) подчеркивают, что МАК - это лишь инструмент, который не работает сам по себе.

Тем не менее, ни в одном из рассмотренных источников, нам не удалось обнаружить четкое описание и классификацию механизмов, которые обеспечивают эффективность МАК как психологического инструмента, что побудило нас к разработке данного вопроса. 


\section{Механизмы, лежащие в основе использования МАК}

Начнем с описания двух базовых защитных механизмов, которые мешают психологической проработке проблемы на вербальном осознанном уровне.

Это вытеснение, которое проявляется в забывании или игнорировании неприятных воспоминаний, информации, и диссоциация, в результате которой человек отделяет от себя неприятные переживания, воспоминания, как будто бы все это происходило не с ним. При диссоциации телесные ощущения, образы восприятия / памяти отделяются от эмоций. Получается, что человек ведет себя так, что это не соответствует «нормальной» реакции, как будто бы ничего не происходило. Диссоциация, как правило, проявляется в ситуациях очень сильной эмоциональной травмы. Помимо «специальных» защитных механизмов, бывает и так, что в связи с низким уровнем образованности, неразвитой рефлексией, отсутствием психологических знаний, человек как бы не специально, но сам не может осознать, что и почему с ним происходит. Независимо от того, какой механизм психологической защиты обеспечивает блокировку травмирующего содержания, на эмоциональном и/или соматическом уровне оно будет иметь проявления.

Рассмотрим механизмы, которые специалист может использовать для обнаружения актуальных проблем клиента и для оказания ему помощи.

Ассоциации - это базовый механизм в работе с МАК.

Ассоциация - это связь между двумя любыми содержаниями психики (представлениями, мыслями, ощущениями, эмоциями и т. п.), при которой предъявление одного автоматически обнаруживается и второе. Ассоциации формируются у каждого индивидуально на основе условных рефлексов, т.е. позитивного или негативного подкрепления. Ассоциации могут «замыкаться» на основе: сходства (обозначаются синонимами: страх - ужас), контраста (в речи обозначаются антонимами: страх - спокойствие), смежности появления в пространстве и/или времени (страх слезы), причинно-следственных связей (боль - страх).

В свою очередь по эмоциональной окраске ассоциации могут быть эмоционально окрашенными (положительными, отрицательным, амбивалентными) или нейтральными. Знак, или валентность, ассоциации определяется соотношением ассоциируемого объекта с удовлетворением или фрустрацией значимых потребностей и мотивов. Нейтральные ассоциации формируются на основе системы значений, усвоенных человеком (белый медведь - снег, холод). Также можно выделить относительно нейтральные ассоциации, которые возникают в ответ на стимул, который раньше был значимым, а на данный момент уже не связан с актуальными мотивами или проблемами.

При этом в рамках психологической работы с МАК ассоциации, которые «выдает» клиент, глядя на карту, важны не сами по себе, а как механизм, связанный с проекциями.

Проекция - это неосознаваемое приписывание человеком другим людям/ внешним явлениями / объектам значимых для него мотивов, эмоций, состояний, качеств и т.П. При проекции восприятие мира искажается таким образом, что начинает отражать не объективную реальность, а особенности воспринимающего человека. Приписывание клиентом образу на карте определенного смысла (действий, мыслей, слов) рассматривается как одна из форм проекции неосознаваемого им актуального содержимого собственной психики (Ингерлейб, 2020). Промежуточное место занимает механизм идентификации, который обнаруживается в том, что человек соотносит себя с конкретными объектами или персонажами, изображенными на карточке. С одной стороны, он может актуализироваться вместе с проекцией и выступать как механизм, позволяющий обнаружить проблему (Попова и Милорадова, 2016). А с другой стороны целенаправленно побуждаться специалистом для решения проблемы.

Далее рассмотрим механизмы, обеспечивающие собственно терапевтический эффект MAK.

Осознание - того или иного проблемного содержания обнаруживается в способности выразить осознаваемое словами или символически - подобрать карточку. В некоторых случаях, когда проблемное содержание связано с сильными негативными переживаниями, погружение может быть опасным для клиента. В этом случае механизм диссоциации, который мы упомянули как защитный и мешающий решению проблемы, может быть использован специалистом как 
терапевтический, когда работа строится за счет отделения и вынесения травматического опыта «во вне», за счет его «материализации» (Трунов, 1997). Так, выражение состояния / сути ситуации с помощью МАК позволяет клиенту занять позицию отстраненного наблюдателя относительно собственных чувств, мыслей, поступков. В дальнейшем это может усиливать чувство субъектности клиента, что также ускорит решение проблемы. Так как рассказ строится про «картинку», а не про самого человека, создается безопасный контекст для реконструкции психотравмирующих событий, поиска решений и путей выхода из ситуации.

Децентращия как терапевтический механизм МАК, позволяет преодолеть субъективность клиента в восприятии проблемной ситуации. За счет децентрации происходит изменение точки зрения, позиции человека в результате столкновения, сопоставления и интеграции ее с позициями, отличными от собственной. Этот механизм может обеспечиваться и за счет упомянутой выше идентификации. В этом контексте идентификация - не просто механизм, а необходимый этап психологической работы с МАК. При этом идентификация может осуществляться на различных «уровнях»: как идентификация себя с отдельными образами; узнавание в образах МАК соответствующих проблем; идентификация обнаруженных с помощью МАК способов решения проблемы, перенос результата метафорической работы в реальную жизнь (Попова и Милорадова, 2014). В целом можно заключить, что если не произошла идентификация, то клиент будет воспринимать обсуждаемые карточки отвлеченно, как не имеющие отношения к себе.

Однако так или иначе специалист ведет клиента от осознания к осмыслению. Суть этого процесса в том, что человек осознает не какую-то информацию саму по себе, но устанавливает, как она связана с другой информацией. Осмысление обеспечивает понимание клиентом причин и следствий, сходств между событиями, логики поведения других людей и своих действий и т.п.

В терминах синергетики МАК стимулируют определение (осознание) параметров порядка, которые запускают процессы самоорганизации клиента (Казанцева, 2017). В процессе работы с картами определяется «ценностно-смысловая структура ситуации» (Тихомиров), в рамках которой обнаруживаются (порождаются) новые смыслы, персональные ценности, направляющие мыслительный процесс и задающих вектор дальнейшей активности человека. При этом, как отмечает В. Е. Клочко (2008), смыслы могут возникать как бы «сами по себе». Это означает, что они порождаются в процессе работы с МАК, но не самой этой деятельностью непосредственно. Они не порождаются сознанием, но дислоцируются на предметах, составляющих объективные условия деятельности и считываются эмоциями в форме инсайта (Клочко, 2008). Таким образом при работе с МАК в поле ясного сознания попадает только то, что уже имеет смысл для человека. Данный эффект исследователи обозначают как смыслообразующую функцию МАК (Казанцева, 2017). В качестве сходных механизмов можно обозначить пару децентрация / переосмысление (рефрейминг). Рефрейминг рассматривается как необходимый этап работы, обеспечивающий действительное понимание и принятие проблемной ситуации (Казанцева, 2017). В этом плане метафора в МАК скорее выступает как продукт осознания и осмысления опыта. В основе метафоризации, как механизма продуцирования нового содержания сознания, лежит сравнение образа (переживания) с каким-то другим на основе общих признаков. При этом осознание (в том числе через метафору), может быть результатом планомерных размышлений и долгосрочной работ с картами, а может появляться в сознании в форме «инсайта», как мгновенная реакция на ту или иную карточку. Рассмотрение же метафоризации в контексте работы с МАК в качестве отдельного механизма кажется нам нецелесообразным.

Заключение. Проведенный анализ позволяет заключить, что метафорические ассоциативные карты - это научно обоснованный инструмент оказания психологической помощи, который будет эффективным только в руках специалиста, знающего закономерности и понимающего психологические механизмы, стоящие за отдельными стратегиями и техниками работы с МАК. Позиционирование МАК как инструмента, доступного любому человеку, независимо от его образования и исключительно как набора карточек вкупе с возможными техниками, не только повышает вероятность того, что проводимая работа будет неэффективной, но и создает очевидную угрозу безопасности клиента.

Решение видится в профессиональной подготовке специалистов, работающих с МАК, обеспечивающей четкое понимание психологических механизмов, лежащих в основе 
использования данного инструмента, особенностей и разграничении использования МАК как инструмента в профессиональной психологической помощи и игрового, вспомогательного, творческого материала в руках специалистов непсихологического профиля.

\section{СПИСОК ССЫЛОК}

Динкель, О. Л., Сорокина, Л. А. (2013). Опыт применения метафорических ассоциативных карт в комплексной терапии расстройств адаптации. Комплексные проблемы сердечнососудистых заболеваний. (3), 105-107.

Ингерлейб, И. (2020) Метафорические ассоциативные карты. Полный курс для практики. СанктПетербург: Питер.

Казанцева, Е. В. (2017) Метафорические ассоциативные карты как «Магическая» психотерапевтическая К практика. Концепm, 2017, $1 . \quad$ Взято $3 \mathrm{http} / /$ cyberleninka.ru/article/n/metaforicheskie-assotsiativnye-karty-kak-magicheskayapsihoterapevticheskaya-praktika.

Кац, Г.Б., Мухаматулина, Е. А. (2016) Метафорические карты. Руководство для психолога. Москва: Генезис.

Киршке, В. (2010) Клубника за окном. Ассоциативные карты для коммуникации и творчества. Kirchzarten: $\mathrm{OH}$ Verglad.

Клочко, В.Е. (2008) Постнеклассическая наука и проблема объяснения в психологии. Взято 3 http://www.lib.tsu.ru/mminfo/000063105/305/image/305-157-164.pdf.

Милорадова, Н.Е., Попова Г. В. (2016) Об алгоритме создания новых колод метафорических ассоциативных карт. Вестник по педагогике и психологии Южной Сибири, 3, 149-161.

Морозовская, Е. (2015) Мир проективных карт. Обзор колод, упражнения, тренинги. Москва: Генезис.

Олифирович, Н. И., Малейчук, Г.Н.(2018) Проективные сказочные картыл. Санкт-Петербург: Речь.

Попова, Г.В., Милорадова, Н. Е. (2014). Психологические механизмы применения метафорических ассоциативных карт в индивидуальном консультировании. Взято 3 https://oh-cards-institute.org/wp-content/uploads/ 2014/07/Попова-и-МилорадоваПсихологические-механизмы.

Трунов, Д. (1997) Использование метафор в психотерапевтической работе. Журнал практического психолога, 1, 14-20.

Ушакова, Т. О. (2016) Метафорические арт-терапевтические инструменты в работе с детьми и подростками. Взято з https://www.youtube.com/watch?v $=6 \mathrm{STrYdeVa3Q}$.

Ушакова, Т. О. (2017) Метафорические карты: возможности и ограничения. Взято 3 https://psy.su/psyche/projects/1894/.

\section{REFERENCES:}

Dinkel, O. L. Sorokina, L. A. (2013). Opyt primeneniya metaforicheskikh assotsiativnykh kart v kompleksnoy terapii rasstroystv adaptatsii. Kompleksnyye problemy serdechno-sosudistykh zabolevaniy. (3). 105-107.

Ingerleyb. I. (2020) Metaforicheskiye assotsiativnyye karty. Polnyy kurs dlya praktiki. Sankt-Peterburg: Piter.

Kazantseva, E. V. (2017) Metaforicheskiye assotsiativnyye karty kak «Magicheskaya» psikhoterapevticheskaya praktika. Kontsept. 2017. 1. Vzyato z http://cyberleninka.ru/article/n/metaforicheskie-assotsiativnye-karty-kak-magicheskayapsihoterapevticheskaya-praktika.

Kats, G. B.. Mukhamatulina, E. A. (2016) Metaforicheskiye karty. Rukovodstvo dlya psikhologa. Moskva: Genezis.

Kirshke. V. (2010) Klubnika za oknom. Assotsiativnyye karty dlya kommunikatsii i tvorchestva. Kirchzarten: $\mathrm{OH}$ Verglad. 
Klochko, V. E. (2008) Postneklassicheskaya nauka i problema obyasneniya v psikhologii. Vzyato $\mathrm{z}$ http://www.lib.tsu.ru/mminfo/000063105/305/image/ 305-157-164.pdf.

Miloradova. N. E.. Popova G. V. (2016) Ob algoritme sozdaniya novykh kolod metaforicheskikh assotsiativnykh kart. Vestnik po pedagogike i psikhologii Yuzhnoy Sibiri. 3. 149-161.

Morozovskaya. E. (2015) Mir proyektivnykh kart. Obzor kolod. uprazhneniya. treningi. Moskva: Genezis.

Olifirovich. N. I. Maleychuk. G. N. (2018) Proyektivnyye skazochnyye karty. Sankt-Peterburg: Rech.

Popova. G. V. Miloradova. N. E. (2014). Psikhologicheskiye mekhanizmy primeneniya metaforicheskikh assotsiativnykh kart $\mathrm{v}$ individualnom konsultirovanii. Vzyato $\mathrm{z}$ https://oh-cards-institute.org/wpcontent/uploads/ 2014/07/Popova-i-Miloradova-Psikhologicheskiye-mekhanizmy.

Trunov. D. (1997) Ispolzovaniye metafor $\mathrm{v}$ psikhoterapevticheskoy rabote. Zhurnal prakticheskogo psikhologa. 1. 14-20.

Ushakova. T. O. (2016) Metaforicheskiye art-terapevticheskiye instrumenty $\mathrm{v}$ rabote $\mathrm{s}$ detmi i podrostkami. Vzyato z https://www.youtube.com/watch?v =6STrYdeVa3Q.

Ushakova. T. O. (2017) Metaforicheskiye karty: vozmozhnosti i ogranicheniya. Vzyato z https://psy.su/psyche/projects/1894/.

\title{
АНАЛІЗ ПОМИЛКОВИХ ПОГЛЯДІВ ЩОДО МЕТАФОРИЧНИХ АСОЦІАТИВНИХ КАРТ ЯК ІНСТРУМЕНТУ ПСИХОЛОГІЧНОЇ ДОПОМОГИ
}

\author{
Олена Марченко \\ кандидат психологічних наук, \\ доцент, доцент кафедри психології \\ Брестського державного університету \\ імені О.С. Пушкіна \\ http://orcid.org/0000-0002-1671-584X. \\ DOI https://doi.org/10.35619/prap_rv.vi14.164
}

\begin{abstract}
Анотація. У статті розглядається проблема використання асочіативних метафоричних карт в роботі психолога. Проведено аналіз найбільш поширених помилок у роботі з ичим інструментом. Пояснені причини їх виникнення та описані можливі способи їх подолання. Доведено, щчо иче надійний та апробований психологічний інструмент, дієвість якого має чітке наукове обтрунтування, проте зазначається, щуо метафоричні асоиіативні карти не можуть розглядатися в якості окремого діагностичного інструменту.

Автором систематизовано основні переваги метафоричних асочіативних карт в рамках психологічного консультування та психотерапї (широкий спектр завдань, форм роботи, можливість використання фахівцями різних психологічних напрямків; екологічність для клієнта, залучення ресурсів свідомості і несвідомого для вирішення проблеми; прискорення вирішення різних завдань; створення загального символічного коду для клієнта і фахівця; гнучкі правила роботи; привабливість для клієнтів різних вікових груп).

Розглянуто основні обмеження і протипоказання до застосування изього інструменту в психологічній практиці. Описано механізми психологічного захисту, що можуть бути нівельовані за допомогою метафоричних асочіативних карт (витіснення, дисочіачія), та ключові механізми, щзо забезпечують актуалізацію проблем клієнта (асоціація, проекція, ідентифікація) $і$ власне терапевтичні механізми карт (дисоціація, усвідомлення, децентрація, метафоризація, осмислення).
\end{abstract}

Ключові слова: метафоричні асочіативні карти, консультування, психологічний інструментарій, захисні психологічні механізми. 


\title{
ANALYSIS OF MISCONCEPTIONS REGARDING METAPHORIC ASSOCIATIVE CARDS AS A PSYCHOLOGICAL AID TOOL
}

\author{
Alena Marchanka \\ Candidate of psychological sciences, \\ associate professor at the Department of psychology \\ Brest State A.S. Pushkin University \\ http://orcid.org/0000-0002-1671-584X. \\ DOI https://doi.org/10.35619/prap_rv.vi14.164
}

\begin{abstract}
The article presents an analysis of the most common misconceptions about metaphorical associative cards. The reasons for their occurrence among clients and specialists themselves are explained, as well as possible ways to overcome them are described. It is shown that this is not a new, but an approved psychological tool, the effectiveness of which has a strictly scientific, and not magical justification. The author clarified why metaphorical associative cards themselves could not be considered as a diagnostic tool. The need for a comprehensive analysis of the verbal and non-verbal parameters of the client's activity is indicated. It is pointed out in the article that the client's choice of cards cannot have unambiguous interpretations and generally is of a secondary nature.

The advantages of metaphorical associative cards are systematized within the framework of psychological counseling and psychotherapy (a wide range of tasks, forms of work, the possibility of using various psychological areas; environmental friendliness for the client; attracting resources of consciousness and the unconscious to solve the problem; accelerating the solution of various problems; creating a common symbolic code for the client and specialist; flexible working rules; attractiveness for customers of different ages).

The main limitations and contraindications to the use of this tool in psychological practice are considered. It is considered which psychological defense mechanisms can be overcome with the help of metaphorical associative maps (displacement, dissociation). The article describes the key mechanisms which help to ensure the actualization of problems of the client (associations, projection, identification) and the actual mechanisms of therapeutic cards (dissociation, awareness, decentration, metaphorization, reflection).
\end{abstract}

Key words: metaphorical associative cards, counseling, psychological defense mechanisms, psychological aid tools. 